\title{
The influence of surface composition of carbon nanotubes on the photobioelectrochemical activity of thylakoid bioanodes mediated by osmium-complex modified redox polymer
}

Pankratov, Dmitrii; Zhao, Jianming; Nur, Mohammed Ahmed; Shen, Fei; Leech, Dónal ; Chi, Qijin; Pantrakova, Galina; Gorton, Lo

Published in:

Electrochimica Acta

Link to article, DOI:

10.1016/j.electacta.2019.04.097

Publication date:

2019

Document Version

Peer reviewed version

Link back to DTU Orbit

Citation (APA):

Pankratov, D., Zhao, J., Nur, M. A., Shen, F., Leech, D., Chi, Q., Pantrakova, G., \& Gorton, L. (2019). The influence of surface composition of carbon nanotubes on the photobioelectrochemical activity of thylakoid bioanodes mediated by osmium-complex modified redox polymer. Electrochimica Acta, 310, 20-25. https://doi.org/10.1016/j.electacta.2019.04.097

\section{General rights}

Copyright and moral rights for the publications made accessible in the public portal are retained by the authors and/or other copyright owners and it is a condition of accessing publications that users recognise and abide by the legal requirements associated with these rights.

- Users may download and print one copy of any publication from the public portal for the purpose of private study or research.

- You may not further distribute the material or use it for any profit-making activity or commercial gain

- You may freely distribute the URL identifying the publication in the public portal 


\section{Accepted Manuscript}

The influence of surface composition of carbon nanotubes on the photobioelectrochemical activity of thylakoid bioanodes mediated by osmium-complex modified redox polymer

Dmitry Pankratov, Jianming Zhao, Mohammed Ahmed Nur, Fei Shen, Dónal Leech,

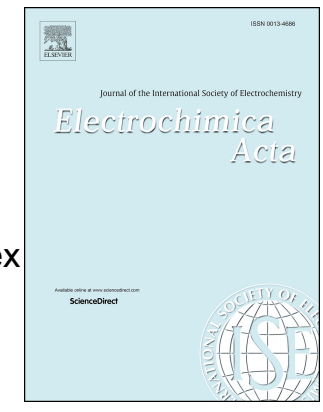
Qijin Chi, Galina Pankratova, Lo Gorton

PII: S0013-4686(19)30783-2

DOI: https://doi.org/10.1016/j.electacta.2019.04.097

Reference: $\quad$ EA 34045

To appear in: Electrochimica Acta

Received Date: 23 December 2018

Revised Date: 14 April 2019

Accepted Date: 15 April 2019

Please cite this article as: D. Pankratov, J. Zhao, M.A. Nur, F. Shen, Dó. Leech, Q. Chi, G. Pankratova, L. Gorton, The influence of surface composition of carbon nanotubes on the photobioelectrochemical activity of thylakoid bioanodes mediated by osmium-complex modified redox polymer, Electrochimica Acta (2019), doi: https://doi.org/10.1016/j.electacta.2019.04.097.

This is a PDF file of an unedited manuscript that has been accepted for publication. As a service to our customers we are providing this early version of the manuscript. The manuscript will undergo copyediting, typesetting, and review of the resulting proof before it is published in its final form. Please note that during the production process errors may be discovered which could affect the content, and all legal disclaimers that apply to the journal pertain. 
The influence of surface composition of carbon nanotubes on the photobioelectrochemical activity of thylakoid bioanodes mediated by osmium-complex modified redox polymer

Dmitry Pankratov,,$^{\dagger}$ Jianming Zhao, ${ }^{\dagger}$ Mohammed Ahmed Nur, ${ }^{\ddagger}$ Fei Shen, ${ }^{\dagger}$ Dónal Leech, ${ }^{\S}$ Qijin

Chi, ${ }^{\dagger}$ Galina Pankratova, ${ }^{*}$ and Lo Gorton $*^{*}$

${ }^{\dagger}$ Department of Chemistry, Technical University of Denmark, DK-2800 Kongens Lyngby,

Denmark

${ }^{\ddagger}$ Department of Biochemistry and Structural Biology, Lund University, P.O. Box 124, SE-22100

Lund, Sweden

${ }^{\S}$ School of Chemistry and Ryan Institute, National, University of Ireland Galway, Galway, Ireland

* Corresponding author. E-mail: lo.gorton@ biochemistry.lu.se

\section{Abstract}

A combination of photosynthetic biocatalysts with high surface area conductive materials mediated by an osmium-complex modified redox polymer (OsRP) holds promising features for the development of sustainable "green" systems for solar energy conversion. In this work we performed a comparative study of two types of carbon nanotubes (CNTs) synthesized by pyrolysis of polymeric precursors. Both CNTs were of similar morphology, but had a different surface $\mathrm{C} / \mathrm{O}$ ratio. The CNTs were utilized as a support for immobilization of thylakoid membranes, electrochemically wired through the OsRP. The photobioanodes based on the CNTs with a higher $\mathrm{C} / \mathrm{O}$ ratio exhibit a higher maximum photocurrent density of $97.1 \pm 8.3 \mu \mathrm{A} \mathrm{cm}^{-2}$ at a light intensity of $400 \mathrm{~W} \mathrm{~m}^{-2}$ with reduced charge transfer resistance, but had lower operational stability. Our results demonstrate the significance of a complex investigation of electrochemical communication between the photosynthetic component, the redox mediator and the support 
nanomaterial and may offer new opportunities for designing and optimization of mediated bioelectrochemical systems.

Keywords: thylakoid membrane, carbon nanotube, osmium-complex modified redox polymer, photobioelectrochemical cell, solar energy conversion

\section{Introduction}

Electron transfer processes occurring between the photosynthetic redox active component and electrode surfaces are one of the most important aspects in development of highly efficient bioelectrochemical systems for conversion of light energy into electric power, sensing or optoelectronic applications [1, 2].

A significant step forward in the development of photosynthetic bioelectrochemical systems was made by the employment of surface-confined redox polymers (RPs) as mediators to facilitate electron transfer processes between the bioelement and the electrode surface [3]. The most widely known and investigated RPs utilized for the entrapment of biocatalysts are based on Oscomplex modified poly(vinyl imidazole)s and poly(vinyl pyridine)s polymeric backbones (OsRPs) [4]. Effective employment of OsRPs in photobioelectrodes leading to the enhancement of the photobioelectrocatalytic current output has been demonstrated both for whole prokaryotic [5-7] and eukaryotic cells [8], as well as for separate cellular components, viz. photosynthetic protein complexes [9-11] and thylakoid membranes (TMs) [12, 13].

Among the available electrode materials today and suitable for fabrication of photobioelectrochemical systems are carbon materials, and in particular carbon nanotubes (CNTs), which can be considered as promising matrices for immobilization of the photosynthetic component owing to their high specific surface area and electrical conductivity, broad possibilities of variable morphology dependent on the method of synthesis, and simplicity of chemical functionalization [14]. CNTs have been used as a support for the immobilization of TMs from the pioneering work by Calkins et al., where TMs were deposited on the surface of the CNTs and electron transfer occurred in the presence of a soluble redox mediator [15], to the recent example of supercapacitive photobioanodes [16].

Despite the fact that the dependence of the photobioelectrocatalytic activity of the entrapped bioelement on the structure and redox potential $\left(E^{\prime}\right)$ of the OsRP was investigated in several 
works $[12,17]$, the influence of the other side of the electron transfer pathway, i.e., the surface composition of the carbon support, on the overall performance of the photobioelectrodes has not been widely studied to date. Understanding of the complex sequence of electron transfer processes from the initial photoinduced water splitting to the final electron acceptor through the $\mathrm{RP} /$ electrode interface is a crucial attribute to consider together with other factors.

In the current study we aimed at investigating the influence of the surface composition of the CNTs on the energy converting activity of the TMs "wired" to the CNT surface via the OsRP using two types of CNTs of the same morphology, but with different surface C/O ratios.

\section{Experimental}

\subsection{Materials}

3-Aminophenol (99\%), formaldehyde solution (37 wt. \%), ethanol (>99.8\%), tetrahydrofuran (>99.9\%), $\mathrm{NaH}_{2} \mathrm{PO}_{4}, \mathrm{Na}_{2} \mathrm{HPO}_{4}, \mathrm{NaCl}, \mathrm{MgCl}_{2}$ were from Sigma-Aldrich Chemie $\mathrm{GmbH}$ (Steinheim, Germany). Argon ( $>99 \%$ ) was purchased from AGA Gas AB (Lidingö, Sweden). Diblock copolymer poly(styrene)-b-poly(ethylene oxide) with a molecular weight of the poly(styrene)unit of $19.5 \mathrm{kDa}$, and a molecular weight of the poly(ethylene oxide) unit of $6 \mathrm{kDa}$ ) was from Polymer Source Inc. (Dorval, Canada). All chemicals were of analytical grade and used without further purification. An osmium-complex modified redox polymer (OsRP) $\left.\left[\mathrm{Os}\left(2,2^{\prime} \text {-bipyridine }\right)_{2} \text { (poly-vinylimidazole }\right)_{10} \mathrm{Cl}\right]^{+/ 2+}$ with an $E^{\prime}$ of $+0.42 \pm 0.01 \mathrm{~V}$ vs. standard hydrogen electrode (SHE) was synthesized as reported in [18]. Thylakoid membranes (TMs) from Spinacia oleracea were extracted and purified as described previously [19] and were kept at $-80{ }^{\circ} \mathrm{C}$. The chlorophyll content determined according to ref. [20] was found to be $3.2 \mathrm{mg} \mathrm{mL}^{-}$ 1 .

All solutions were prepared using deionized water purified with a Milli-Q system (Millipore, Bedford, MA, USA). Unless stated otherwise, the experiments were carried out at room temperature $\left(23 \pm 2{ }^{\circ} \mathrm{C}\right)$ in an air saturated $10 \mathrm{mM}$ phosphate buffer solution ( $\left.\mathrm{pH} 7.0\right)$ containing $10 \mathrm{mM} \mathrm{NaCl}$ and $5 \mathrm{mM} \mathrm{MgCl} 2$.

\subsection{Preparation of carbon nanotubes}

CNTs with a controllable morphology were synthesized by pyrolysis of polymeric nanotubes following a previously developed protocol [21] with some modifications. Briefly, $135 \mathrm{mg}$ of PS- 
b-PEO was first dissolved in $8 \mathrm{~mL}$ of tetrahydrofuran, whereafter $24 \mathrm{~mL}$ of $\mathrm{H}_{2} \mathrm{O}$ and $12 \mathrm{~mL}$ of ethanol were added. After stirring for $20 \mathrm{~min}, 235.6 \mathrm{mg}$ of 3-aminophenol was dispersed in the mixture under mild stirring. After stirring for $30 \mathrm{~min}, 0.322 \mathrm{ml}$ of formaldehyde solution was injected to polymerize with 3-aminophenol. The reaction was carried out under vigorous stirring at $20{ }^{\circ} \mathrm{C}$ for $12 \mathrm{~h}$ and then at $70{ }^{\circ} \mathrm{C}$ for $2 \mathrm{~h}$. A yellow solid product was decanted, washed with water, centrifuged twice at $10000 \mathrm{rpm}$ and dried at $85^{\circ} \mathrm{C}$ overnight. Calcination of the obtained product was carried out in a tubular furnace at $350{ }^{\circ} \mathrm{C}$ for $1 \mathrm{~h}$ and $800{ }^{\circ} \mathrm{C}$ for $1 \mathrm{~h}(\mathrm{CNTs}-1)$ or for $10 \mathrm{~h}$ (CNTs-10) under an argon flow.

\subsection{Preparation of working electrodes}

Graphite rods ( $\varnothing 3.05 \mathrm{~mm}$, Alfa Aesar GmbH\& Co KG, Germany) were polished on abrasive paper Tufbak Durite, P1200 (Norton, USA) and rinsed with water. A CNT suspension (5 mg mL'

${ }^{1}$ ) in $10 \mathrm{mM}$ phosphate buffer ( $\mathrm{pH}$ 7.0) was ultrasonicated for $30 \mathrm{~min}$ in a Branson $\mathrm{MH}$ ultrasonic cleaning bath (Fullerton, CA, USA). $5 \mu \mathrm{L}$ of CNT suspension (CNTs-1 or CNTs-10) was dropcast on the graphite surface and left to dry. $7 \mu \mathrm{L}$ of RP solution $\left(10 \mathrm{mg} \mathrm{mL}^{-1}\right)$ was spread over the electrode surface and left for $20 \mathrm{~min}$ to further dry, thereafter the electrode was modified with $1.5 \mu \mathrm{L}$ of TM solution, dried for $4 \mathrm{~min}$ and covered up with a dialysis membrane (Spectrum Laboratories Inc., USA, MWCO: 6-8 kDa) presoaked in buffer. The loaded amounts of the RP and TM were additionally optimized (Figure S1). The electrodes were tested immediately after preparation.

\subsection{Instrumentation and measurements}

All electrochemical measurements were carried out using an Autolab PGSTAT30 potentiostat (EcoChemie, Utrecht, The Netherlands), controlled by the GPES and FRA software, and a threeelectrode configuration, in which the modified graphite electrode, a platinum foil and an $\mathrm{Ag} \mid \mathrm{AgCl}$ (sat. $\mathrm{KCl}$ ) electrodes (Sensortechnik, Meinsberg, Germany) served as working, counter and reference electrodes, respectively. All potentials in this work are presented vs. SHE. The geometrical electrode surface area was used in all calculations to represent the electrochemical characteristics. Electrochemical impedance spectroscopy (EIS) experiments were performed with a voltage amplitude perturbation of $5 \mathrm{mV}$ over a frequency range of $50 \mathrm{kHz}-0.1 \mathrm{~Hz}$. Fitting of the impedance data was done using ZSimpWin software from Princeton Applied Research (Oak 
Ridge, TN, USA). All presented data were obtained on at least three independent measurements for each experiment.

The photosynthetic reaction was initiated with a 150W 220V fiber optic illuminator (Titan Tool Supply, Inc., NY, USA). The light intensity of $400 \mathrm{~W} \mathrm{~m}^{-2}$ applied in all photoelectrochemical experiments was calibrated using a light intensity meter (Techtum Lab AB, Umeå, Sweden).

Scanning electron microscopy (SEM) was conducted using a scanning electron microscope FEI Quanta 200 (FEI Company, USA) equipped with an electron transfer detector in high vacuum mode at $30 \mathrm{kV}$ accelerating voltage. Transmission electron microscopy (TEM) was performed using a FEI Tecnai T20 G $200 \mathrm{kV}$ microscope (FEI Company, USA). X-ray photoelectronic spectroscopy (XPS) was carried out at room temperature using a JPS 9010 TR (JEOL Ltd., Japan) instrument with an $\mathrm{Mg} \mathrm{K} \alpha \mathrm{X}$-ray source. Thermo Advantage software with a fixed Gaussian/Lorentzian (G/L) ratio was used for data analysis.

\section{Results and discussion}

\subsection{Characterization of carbon nanotubes}

The surface morphology of the two types of CNTs was investigated with SEM and TEM. As expected from the synthesis, both CNTs-1 and CNTs-10 have a worm-like cylindrical morphology with open ends, an outer diameter of ca. $50 \mathrm{~nm}$ and an inner diameter of about 25 $\mathrm{nm}$ gathered into three-dimensional carbon support during drying of the suspension (Figures 1A, B and 2A). As it has been previously shown in ref. [21], the morphology of the CNTs does not depend on the calcination time. When CNTs were modified with OsRP, a uniform coverage of the carbon surface by the mediator was obtained (Figure 1B, C), which retains a well developed surface structure required for a high loading of the biocatalyst.

The chemical composition of the surface of the CNTs was performed by XPS. As can be seen from the general survey spectra presented in Figure 2B, the CNTs were composed mainly of carbon $(285 \mathrm{eV})$, oxygen $(530 \mathrm{eV})$ and nitrogen $(400 \mathrm{eV})$, coinciding with the elemental composition of the synthetic precursors. A longer thermal treatment results in an increased carbon content (from $84.8 \pm 0.8 \%$ to $89.3 \pm 0.4 \%$ ) and a decreased oxygen percentage (from 11.1 $\pm 0.3 \%$ to $6.9 \pm 0.2 \%$ ), whereas the amount of nitrogen was kept stable at around $4 \%$. The deconvoluted $\mathrm{C} 1 \mathrm{~s}$ spectra for both CNTs are dominated by a very intense peak assigned to the 
aromatic $\mathrm{sp}^{2}$ structure, located at binding energies of $284.6 \mathrm{eV}(75.7 \pm 0.6 \%$ and $80.2 \pm 0.4 \%$ for CNTs-1 and CNTs-10, respectively). The peak at $286.2 \mathrm{eV}$ can be assigned to the C-O/C-N single bonds [22] with a concentration of $11.6 \pm 0.4 \%$ for the CNTs- 1 , which slightly increased to $14.0 \pm 0.4 \%$ for the CNTs-10. Conversely, the $\mathrm{C}=\mathrm{O}$ peak decreased by ca. $4 \%$ and the $\mathrm{COOH}$ peak disappeared after the longer thermal treatment (Figure 2C, D).

The capacitance density calculated from cyclic voltammograms (CVs) was $18.88 \pm 1.61$ and $12.21 \pm 0.92 \mathrm{mF} \mathrm{cm}^{-2}$ for the electrodes based on the CNTs-1 and CNTs-10, respectively. The capacitance density for both CNTs achieved in this work was up to 2.6-fold higher compared to that for the amidated and carboxylated CNTs previously employed previously as a support for TMs-based photobioanodes [16] and the Toray carbon paper that has been commonly used for photobioanode fabrication [23]. The capacitance density achieved in neutral buffer solution also outperformed many commercially available analogues from different sources [24]. The reduced capacitance in case of the CNTs-10 can be attributed to the lower concentration of charged groups on its surface.

Both types of CNTs modified with the OsRP exhibit a similar initial open circuit potential (OCP) of $0.443 \pm 0.001 \mathrm{~V}$ without any notable influence of illumination on the OCP values or polymer leakage from the CNT surface ( $>96 \%$ of residual capacitance after 30 consecutive CVs for both OsRP/CNTs composites, Figure S2). The immobilized TMs on the OsRP/CNTs surface displayed a decreased OCP up to $0.430 \pm 0.001 \mathrm{~V}$ equal for both CNTs. The OCP value of the OsRP/CNTs corresponds to the value recently obtained for the TMs directly immobilized on the CNT surface [16] and is close to the redox potential of the used OsRP. Under illumination the potential of the bioelectrodes decreased to $0.355 \pm 0.002 \mathrm{~V}$ and $0.316 \pm 0.002 \mathrm{~V}$, respectively, for the TMs/OsRP/CNTs-1 and TMs/OsRP/CNTs-10 photobioanodes due to the reduction of Os ${ }^{3+}$ in the OsRP matrix by the electrons generated from the water splitting. Assuming that the OCP before illumination corresponds to an equal amount of $\mathrm{Os}^{3+}$ and $\mathrm{Os}^{2+}$ in the polymer matrix, similarly to the recently disclosed concept of Nernstian biosupercapacitor [25-27], the registered changes in potential are determined by an $\mathrm{Os}^{2+} / \mathrm{Os}^{3+}$ ratio of 18.7 and 85.6 for the TMs/OsRP/CNTs-1 and the TMs/OsRP/CNTs-10 electrodes, respectively, which indicates a significantly higher activity of the photobioanodes in the absence of an externally applied potential, when the CNTs-10 were employed. Linear sweep voltammograms for the TMs/OsRP/CNTs electrodes show an increase in photocurrent at potentials higher than that for 
anodic redox peak of the OsRP confirming the ability of bound oxidized osmium-complex moieties to accept electrons generated in the TMs under illumination due to electrochemical "wiring" of TMs to the OsRP and shuttle electrons through the OsRP matrix to the electrode surface (Figure S3).

The photobioelectrocatalytic activity of the TMs was further investigated amperometrically at an applied potential of $0.6 \mathrm{~V}$, similarly to previous works $[28,29]$. The background photocurrent contribution from the OsRP/CNTs electrodes (ca. $0.3 \mu \mathrm{A} \mathrm{cm}{ }^{-2}$ for both types of CNTs) was subtracted from the amperograms presented in Figure 4A. The maximum photobiocurrent density achieved for the TMs/OsRP/CNTs-10 and the TMs/OsRP/CNTs-1 electrodes was $97.1 \pm 8.3$ and $87.4 \pm 1.9 \mu \mathrm{A} \mathrm{cm}{ }^{-2}$, respectively. The photocurrent density achieved in this study outperforms recent examples of photobioanodes employing immobilized TM, electrochemically "wired" to the electrode materials, viz. carbon-on-quartz transparent electrode chips (up to $71 \mu \mathrm{A}$ $\mathrm{cm}^{-2}$ ) [30], gold microparticles deposited onto carbon screen-printed electrodes $\left(62.5 \mu \mathrm{A} \mathrm{cm}{ }^{-2}\right)$ [31] and an earlier example of a TMs/CNTs composite $\left(68 \mu \mathrm{A} \mathrm{cm}^{-2}\right)$ [15].

Surprisingly, in spite of the higher photocurrent produced during the initial $15 \mathrm{~min}$ of operation, the operational stability of the TMs/OsRP/CNTs-10 electrodes was lower. We attribute such a phenomenon with the lower amount of charged groups in the CNTs-10 facilitating the orientation of the OsRP, when the non-charged polymeric backbones are expanded in closer contact with the CNT surface, whereas the osmium redox centers of the polymer are directed outside. This may result in an increased internal conductivity of the OsRP due to the shortened distance between the redox centers, but has a negative influence on the interaction with the TMs, which leads to the faster damage of the photosynthetic protein complexes with active forms of oxygen $[32,33]$.

The electron transfer processes in the system TMs/OsRP/CNTs were further investigated using EIS under illumination and the same experimental conditions as for the amperometric measurements. Fitting of the recorded data was performed with a satisfactory approximation $\left(\chi<10^{-3}\right.$ for all curves) using the equivalent circuit presented in Figure 4B, which has been successfully employed to describe electron transfer in photobioanodes based on TMs [13, 16] and (in expanded form) for porous electrodes covered with a conductive polymer [34] or microbial bioanodes mediated by the OsRPs [35]. $R_{s}$ and $R_{c t}$ in this model correspond to the electrolyte solution resistance and the charge transfer resistance. The constant phase elements 
$C P E_{d l}$ and $C P E_{\varphi}$ are related to the non-ideal double-layer capacitance and the polarization of the electrode material, respectively.

As can be seen from Table 1, the photobioanodes based on the CNTs-10 can be characterized by the notably lower $R_{c t}$, which defines the higher maximum current output and is in good agreement with a relationship between the charge transport diffusion coefficients for OsRP/CNTs composites (Figure S4). $R_{c t}$ obtained in this work for the TMs/OsRP/CNTs-10 photobioelectrodes is ca. 5 times lower compared to the system, where a planar gold surface was modified with the same amount of OsRP [13], confirming the positive influence of the chemistry and the developed surface structure on the electron transfer processes occurring in the system.

\section{Conclusions}

In the present study for the first time, to the best of our knowledge, CNTs synthetized by pyrolysis of organic precursors were utilized as a matrix for immobilization of photosynthetic biocomponents for their potential utilization in photobioelectrochemical systems. The photobioanodes employing TMs electrochemically "wired" to the surface of the CNTs via OsRP exhibit a maximum photocurrent density of $97.1 \pm 8.3 \mu \mathrm{A} \mathrm{cm}^{-2}$, which is the highest performance value reported up to date for any photobioanode employing immobilized TMs. The complex influence of the surface composition of the three-dimensional support on the performance of the mediated bioelectrodes should be taken into account for further development and optimization of highly efficient bioelectrochemical systems for solar energy conversion. The findings reported in this work may be extrapolated to other mediated systems employing 3D carbon surfaces, such as biosensors, enzymatic and microbial fuel cells.

\section{Acknowledgement}

This work was financially supported by the People Programme (Marie Curie Actions) of the European Union's Seventh Framework Programme (FP7/2007-2013) under REA Grant Agreement No. 609405 (Ørsted-COFUND Postdoc fellowship at DTU), the Swedish Research Council (Project No. 2014-5908), the Independent Research Fund Denmark-Nature Sciences (Project No. 7014-00302B), Science Foundation Ireland (Project 15/TIDA/2887), and from the Villum Foundation for a postdoctoral program. The authors thank Prof. Hans-Erik Åkerlund 
(Department of Biochemistry and Structural Biology, Lund University, Lund, Sweden) for providing the TMs.

\section{References}

[1] R. Tel-Vered, I. Willner, Photo-bioelectrochemical cells for energy conversion, sensing, and optoelectronic applications, ChemElectroChem, 1 (2014) 1778-1797.

[2] M. Rasmussen, S.D. Minteer, Photobioelectrochemistry: Solar energy conversion and biofuel production with photosynthetic catalysts, J. Electrochem. Soc., 161 (2014) H647-H655.

[3] A. Ruff, Redox polymers in bioelectrochemistry: Common playgrounds and novel concepts, Curr. Opin. Electrochem., 5 (2017) 66-73.

[4] A. Heller, Electron-conducting redox hydrogels: design, characteristics and synthesis, Curr. Opin. Chem. Biol., 10 (2006) 664-672.

[5] K. Hasan, S.A. Patil, K. Górecki, D. Leech, C. Hägerhäll, L. Gorton, Electrochemical communication between heterotrophically grown Rhodobacter capsulatus with electrodes mediated by an osmium redox polymer, Bioelectrochemistry, 93 (2013) 30-36.

[6] K. Hasan, K.V.R. Reddy, V. Eßmann, K. Górecki, P. Ó Conghaile, W. Schuhmann, D. Leech, C. Hägerhäll, L. Gorton, Electrochemical communication between electrodes and Rhodobacter capsulatus grown in different metabolic modes, Electroanalysis, 27 (2015) 118127.

[7] K. Hasan, H.B. Yildiz, E. Sperling, P. Ó Conghaile, M.A. Packer, D. Leech, C. Hägerhäll, L. Gorton, Photo-electrochemical communication between cyanobacteria (Leptolyngbia sp.) and osmium redox polymer modified electrodes, Phys. Chem. Chem. Phys., 16 (2014) 24676-24680.

[8] K. Hasan, E. Çevik, E. Sperling, M.A. Packer, D. Leech, L. Gorton, Photoelectrochemical wiring of Paulschulzia pseudovolvox (algae) to osmium polymer modified electrodes for harnessing solar energy, Adv. Energy Mater., 5 (2015) 1501100.

[9] K.P. Sokol, D. Mersch, V. Hartmann, J.Z. Zhang, M.M. Nowaczyk, M. Rögner, A. Ruff, W. Schuhmann, N. Plumeré, E. Reisner, Rational wiring of photosystem II to hierarchical indium tin oxide electrodes using redox polymers, Energy Environ. Sci., 9 (2016) 3698-3709.

[10] F.Y. Zhao, V. Hartmann, A. Ruff, M.M. Nowaczyk, M. Rögner, W. Schuhmann, F. Conzuelo, Unravelling electron transfer processes at photosystem 2 embedded in an Os-complex modified redox polymer, Electrochim. Acta, 290 (2018) 451-456.

[11] A. Badura, T. Kothe, W. Schuhmann, M. Rögner, Wiring photosynthetic enzymes to electrodes, Energy Environ. Sci., 4 (2011) 3263-3274.

[12] H. Hamidi, K. Hasan, S.C. Emek, Y. Dilgin, H.-E. Åkerlund, P.-Å. Albertsson, D. Leech, L. Gorton, Photocurrent generation from thylakoid membranes on osmium-redox-polymer-modified electrodes, ChemSusChem, 8 (2015) 990-993. 
[13] G. Pankratova, D. Pankratov, K. Hasan, H.-E. Åkerlund, P.-Å. Albertsson, D. Leech, S. Shleev, L. Gorton, Supercapacitive photo-bioanodes and biosolar cells: a novel approach for solar energy harnessing, Adv. Energy Mater., 7 (2017) 1602285.

[14] I. Mazurenko, A. de Poulpiquet, E. Lojou, Recent developments in high surface area bioelectrodes for enzymatic fuel cells, Curr. Opin. Electrochem., 5 (2017) 74-84.

[15] J.O. Calkins, Y. Umasankar, H. O'Neill, R.P. Ramasamy, High photo-electrochemical activity of thylakoid-carbon nanotube composites for photosynthetic energy conversion, Energy Environ. Sci., 6 (2013) 1891-1900.

[16] D. Pankratov, G. Pankratova, T.P. Dyachkova, P. Falkman, H.-E. Åkerlund, M.D. Toscano, Q. Chi, L. Gorton, Supercapacitive biosolar cell driven by direct electron transfer between photosynthetic membranes and CNT networks with enhanced performance, ACS Energy Lett., 2 (2017) 2635-2639.

[17] F.Y. Zhao, K. Sliozberg, M. Rögner, N. Plumeré, W. Schuhmann, The role of hydrophobicity of Os-complex-modified polymers for photosystem 1 based photocathodes, J. Electrochem. Soc., 161 (2014) H3035-H3041.

[18] E.M. Kober, J.V. Caspar, B.P. Sullivan, T.J. Meyer, Synthetic routes to new polypyridyl complexes of osmium(II), Inorg. Chem., 27 (1988) 4587-4598.

[19] E. Andreasson, P. Svensson, C. Weibull, P.-Å. Albertsson, Separation and characterization of stroma and grana membranes - evidence for heterogeneity in antenna size of both photosystem-I and photosystem-II, Biochim. Biophys. Acta, 936 (1988) 339-350.

[20] R.J. Porra, W.A. Thompson, P.E. Kriedemann, Determination of accurate extinction coefficients and simultaneous equations for assaying chlorophylls $a$ and $b$ extracted with four different solvents: verification of the concentration of chlorophyll standards by atomic absorption spectroscopy, Biochim. Biophys. Acta Bioenerg., 975 (1989) 384-394.

[21] J. Zhao, W. Huang, P. Si, J. Ulstrup, F. Diao, J. Zhang, General syntheses of nanotubes induced by block copolymer self-assembly, Macromol. Rapid Comm., 39 (2018) 1800125.

[22] F. Pogacean, C. Socaci, S. Pruneanu, A.R. Biris, M. Coros, L. Magerusan, G. Katona, R. Turcu, G. Borodi, Graphene based nanomaterials as chemical sensors for hydrogen peroxide - A comparison study of their intrinsic peroxidase catalytic behavior, Sens. Actuat. B, 213 (2015) 474-483.

[23] M. Rasmussen, A. Shrier, S.D. Minteer, High performance thylakoid bio-solar cell using laccase enzymatic biocathodes, Phys. Chem. Chem. Phys., 15 (2013) 9062-9065.

[24] D.V. Pankratov, Y.S. Zeifman, O.V. Morozova, G.P. Shumakovich, I.S. Vasil'eva, S. Shleev, V.O. Popov, A.I. Yaropolov, A comparative study of biocathodes based on multiwall carbon nanotube buckypapers modified with three different multicopper oxidases, Electroanalysis, 25 (2013) 1143-1149.

[25] X. Xiao, P. Ó Conghaile, D. Leech, R. Ludwig, E. Magner, A symmetric supercapacitor/biofuel cell hybrid device based on enzyme-modified nanoporous gold: An autonomous pulse generator, Biosens. Bioelectron., 90 (2017) 96-102. 
[26] F. Conzuelo, N. Marković, A. Ruff, W. Schuhmann, The open circuit voltage in biofuel cells: Nernstian shift in pseudocapacitive electrodes, Angew. Chem. Int. Ed., 57 (2018) 1368113685 .

[27] D. Pankratov, F. Conzuelo, P. Pinyou, S. Alsaoub, W. Schuhmann, S. Shleev, A Nernstian biosupercapacitor, Angew. Chem. Int. Ed., 55 (2016) 15434-15438.

[28] N.D. Kirchhofer, M.A. Rasmussen, F.W. Dahlquist, S.D. Minteer, G.C. Bazan, The photobioelectrochemical activity of thylakoid bioanodes is increased via photocurrent generation and improved contacts by membrane-intercalating conjugated oligoelectrolytes, Energy Environ. Sci., 8 (2015) 2698-2706.

[29] K. Hasan, Y. Dilgin, S.C. Emek, M. Tavahodi, H.-E. Åkerlund, P.-Å. Albertsson, L. Gorton, Photoelectrochemical communication between thylakoid membranes and gold electrodes through different quinone derivatives, ChemElectroChem, 1 (2014) 131-139.

[30] A.-I. Bunea, A. Heiskanen, G. Pankratova, G. Tesei, M. Lund, H.-E. Åkerlund, D. Leech, N.B. Larsen, S.S. Keller, L. Gorton, J. Emnéus, Micropatterned carbon-on-quartz electrode chips for photocurrent generation from thylakoid membranes, ACS Appl. Energy Mater., 1 (2018) 3313-3322.

[31] H. Kanso, G. Pankratova, P. Bollella, D. Leech, D. Hernandez, L. Gorton, Sunlight photocurrent generation from thylakoid membranes on gold nanoparticle modified screen-printed electrodes, J. Electroanal. Chem., 816 (2018) 259-264.

[32] F. Zhao, S. Hardt, V. Hartmann, H. Zhang, M.M. Nowaczyk, M. Rögner, N. Plumeré, W. Schuhmann, F. Conzuelo, Light-induced formation of partially reduced oxygen species limits the lifetime of photosystem 1-based biocathodes, Nat. Commun., 9 (2018) 1973.

[33] A. Melis, Photosystem-II damage and repair cycle in chloroplasts: what modulates the rate of photodamage in vivo?, Trends Plant. Sci., 4 (1999) 130-135.

[34] M.R. Abidian, D.C. Martin, Experimental and theoretical characterization of implantable neural microelectrodes modified with conducting polymer nanotubes, Biomaterials, 29 (2008) 1273-1283.

[35] G. Pankratova, E. Szypulska, D. Pankratov, D. Leech, L. Gorton, Electron transfer between the Gram-positive Enterococcus faecalis bacterium and electrode surface through osmium redox polymers, ChemElectroChem, 6 (2019) 110-113. 
Figure 1. Representative SEM images of (A) pristine CNTs-1, (B) pristine CNTs-10, (C) OsRP modified CNTs-1, and (D) OsRP modified CNTs-10. Magnification: (A, B) $\times 50000$ and (C, D) 140000 .

Figure 2. Representative TEM image (A) and XPS analysis of CNTs (B-D). (B) General survey spectra of CNTs-1 (black curve) and CNTs-10 (red curve). (C) and (D) C1s spectra for the CNTs-1 and CNTs-10, respectively, analyzed in detail; the solid red curves are the measured data and the dashed blue curves are the overall fitting. The curves in other colors correspond to the deconvoluted spectra.

Figure 3. (A) Representative CVs for graphite electrodes modified with CNTs-1 (black curve) and CNTs-10 (red curve). Potential sweep rate: $10 \mathrm{mV} \mathrm{s}^{-1}$. (B) OCP for non-biomodified (dashed curves) and TMs-modified OsRP/CNTs electrodes (solid curves). Black and red curves refer to electrodes based on CNTs-1 and CNTs-10, respectively. Orange and black arrows correspond to "light on" and "light off" conditions, consequently.

Figure 4. (A) Representative amperograms with the background subtracted and (B) typical experimental (dots) and modeled (lines) Nyquist plots at $0.6 \mathrm{~V}$ for the TMs/OsRP/CNTs-1 (black curves) and TMs/OsRP/CNTs-10 (red curves). Inset in (B) shows the equivalent circuit model used in the fitting of the measured data. Orange and black arrows in (A) represent "light on" and "light off" conditions, respectively. 
Table 1. EIS parameters obtained by fitting the impedance spectra presented in Figure 4B using the proposed equivalent circuit for the TMs immobilized on the CNTs- 1 and the CNTs10 based electrodes modified with OsRP.

\begin{tabular}{|l|c|c|c|c|c|c|c|}
\hline & \multirow{2}{*}{$R_{s}, \Omega$} & \multicolumn{2}{|c|}{$C P E_{d l}$} & \multicolumn{2}{|c|}{$C P E_{\varphi}$} & $R_{c t}, \Omega$ & $\chi$ \\
\cline { 3 - 6 } & & $Q_{d l} \cdot 10^{4}, \mathrm{~S} \cdot \mathrm{s}^{\alpha_{\mathrm{dl}}}$ & $\alpha_{d l}$ & $Q_{\varphi} \cdot 10^{4}, \mathrm{~S} \cdot \mathrm{s}^{\alpha_{\mathrm{dl}}}$ & $\alpha_{\varphi}$ & & \\
\hline TMs/OsRP/CNTs-1 & $733 \pm 2$ & $3.09 \pm 0.08$ & $0.63 \pm 0.01$ & $9.72 \pm 1.05$ & $0.65 \pm 0.07$ & $3391 \pm 290$ & 0.88 \\
\hline $\begin{array}{l}\text { TMs/OsRP/CNTs- } \\
10\end{array}$ & $741 \pm 2$ & $2.32 \pm 0.13$ & $0.69 \pm 0.01$ & $6.22 \pm 0.27$ & $0.60 \pm 0.04$ & $2036 \pm 246$ & 2.33 \\
\hline
\end{tabular}




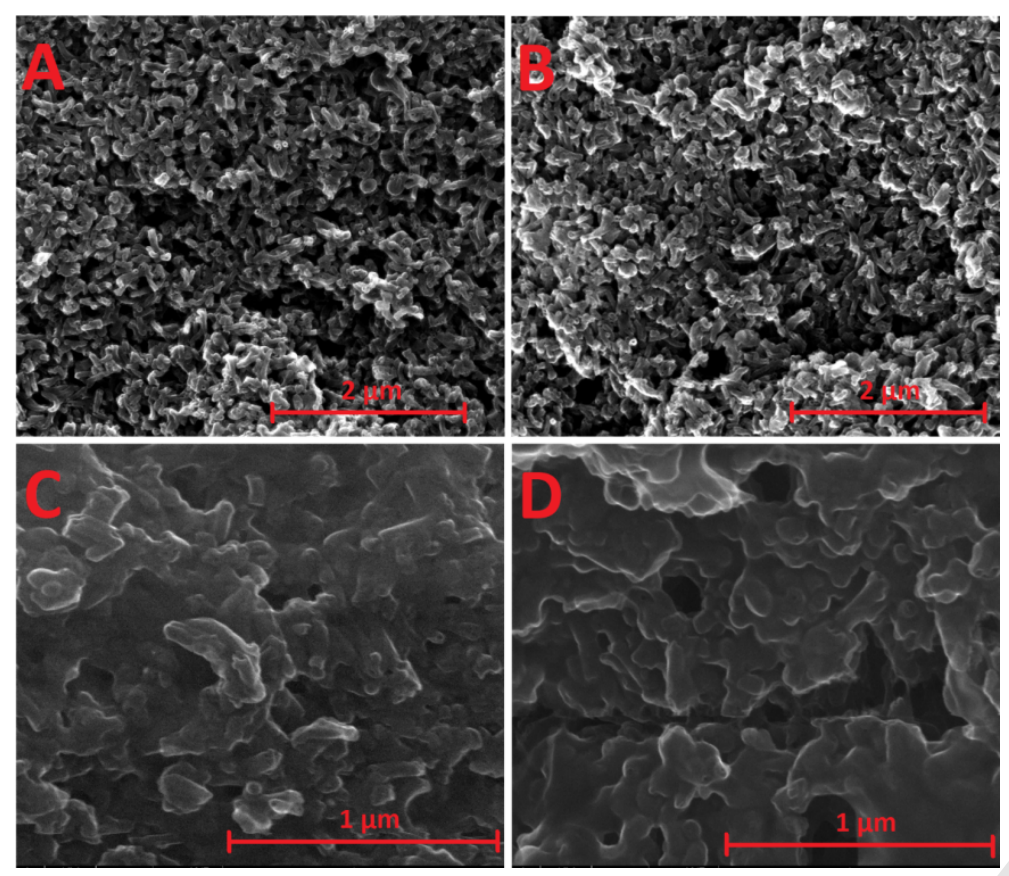



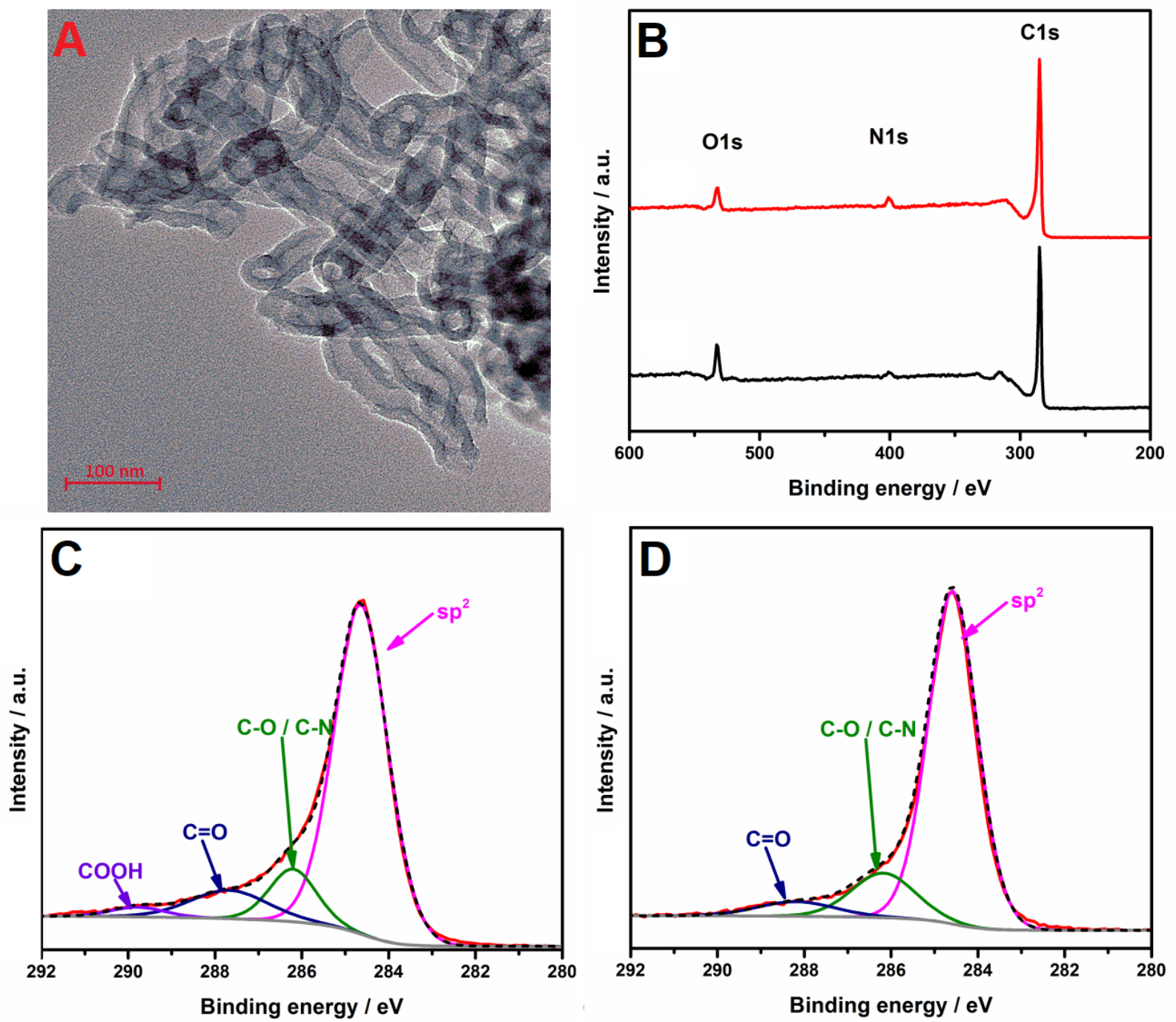
A

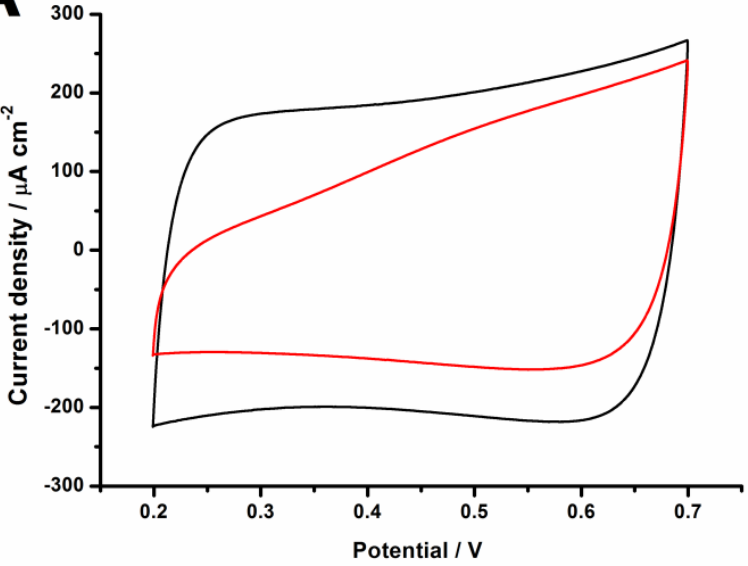

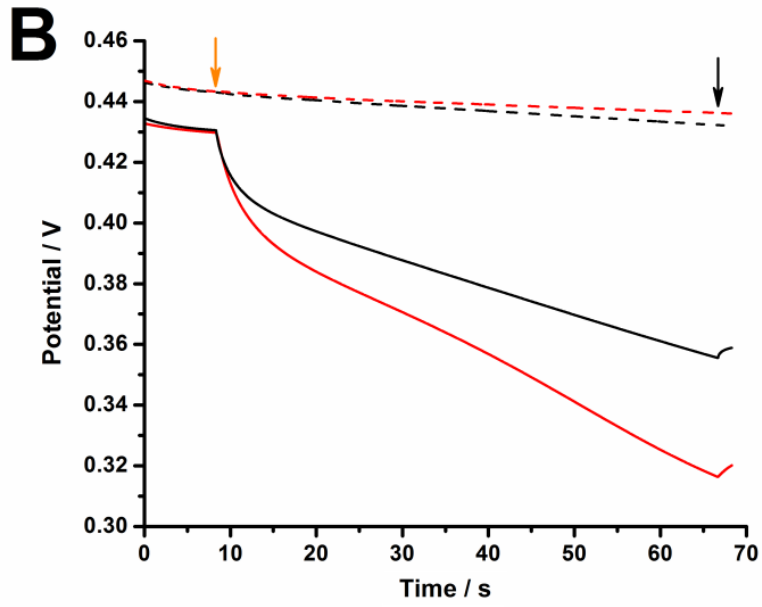



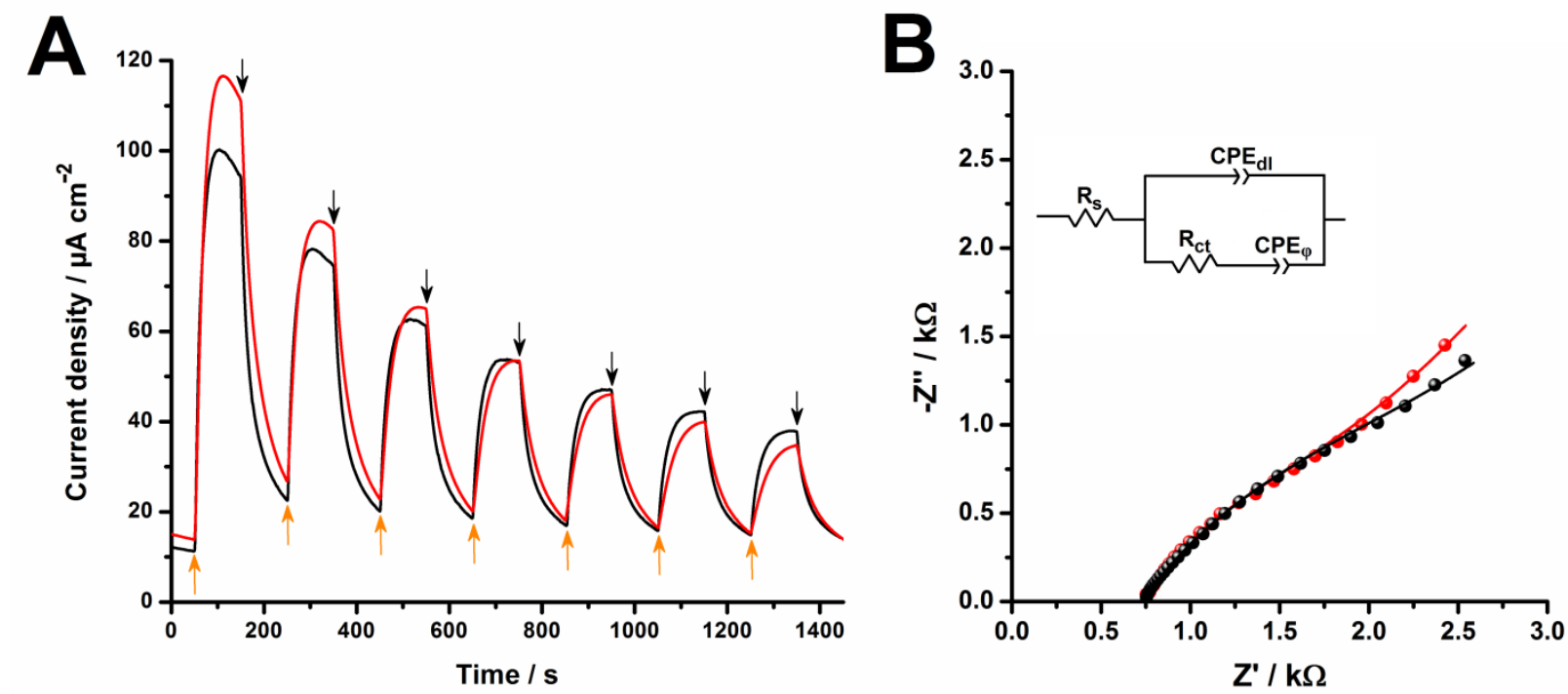